\title{
Development of a quality management system for a machine- building enterprise
}

\author{
Inna P. Bandurina ${ }^{1, *}$, Mikhail A. Bandurin ${ }^{1}$, and Alexander P. Bandurin ${ }^{2}$ \\ ${ }^{1}$ Kuban State Agrarian University named after I.T. Trubilin, Kalinina st, 13/20-161, Krasnodar, Russia \\ ${ }^{2}$ Don State Agrarian University, Dubovskogo st. 46-56, Novocherkassk, Russia
}

\begin{abstract}
The article presents proposals for the development of the quality management system of a machine-building enterprise based on a risk-oriented process approach. The theoretical and methodological foundations of the risk management subsystem formation as the basis of continuous development of the quality management system based on ISO 9000 standards are considered. Methodological recommendations of the development of existing enterprise methods for managing the processes of the quality management system are proposed. A methodology of risk management of quality management system processes has been developed. The practical application of the proposals formulated in the paper is shown by the example of an enterprise engaged in the production of electric traction machines for railway rolling stock. At the present stage of development of machine-building production, insufficient attention is paid to the issue of methodological support for risk management of quality management system processes developed on the basis of ISO 9000 series standards, despite the fact that this direction is very relevant and practically in demand in all industries. It is revealed that the process monitoring system, which is based on monitoring process indicators, information about internal audits, self-assessment of the quality management system, allows you to present a real picture of the state of processes and develop management decisions to improve the effectiveness and improvement of processes and the quality management system. And all the information obtained during process monitoring can be used as input data for managing risks in processes.
\end{abstract}

Keywords: risk-oriented approach, management, enterprise, production

\section{Introduction}

Modern science-intensive production at an industrial enterprise includes the production of products related to the need for more theoretical calculations, scientific research and experiments. Usually, a high-tech production is considered to be one in which research and development work accounts for at least $60 \%$ of all costs associated with preparation and production of products [1]. Therefore, special attention should be paid to product quality, which is one of the three main components that affect the competitiveness of manufactured products, which in turn directly affects the coverage of all $\mathrm{R} \& \mathrm{~d}$ costs and the planned profit from the project [2].

It is recognized that the ISO 9000 series standards [3] are a good tool with a minimal foundation for achieving the main goal of enterprises in the field of designing an effective quality system in order to meet customer requirements. When producing a particular product, obtaining an ISO 9000 series certificate by organizations contributes not only to improving the competitiveness of the product on the market, but also positively forms the business image and reputation of the company [4].

The consumer is increasingly demanding that next to the product certificate, which is considered in this situation only as evidence of the company's engineering capabilities, there is a certificate for the quality system. This confirms that the company has a system that guarantees stable output of products of the quality level that is confirmed by the certificate for the products themselves.

To achieve a stable and competitive position, a machine-building enterprise needs to make timely management decisions that are adequate to changes in the external and internal environment. Therefore, one of the main factors in the development of an organization is the continuous improvement of its quality management system [5].

In connection with the need to switch to a new version of the ISO 9000 series of standards, organizations in various fields of activity, including industrial enterprises, faced the question of combining the already proven "process approach" with a new concept of risk-based thinking [6]. The inherent advantage of this integration is the continuous improvement of the quality management system processes by identifying in advance the "bottlenecks" of processes aimed at preventing the release of nonconforming products and the provision of nonconforming services, which will ultimately increase the satisfaction of consumers and other stakeholders.

* Corresponding author: Chepuraib@gmail.com 
Currently, insufficient attention is paid to the issue of methodological support for risk management of quality management system processes developed on the basis of ISO 9000 series standards, despite the fact that this area is very relevant and practically in demand in all industries.

\section{Figures and tables}

To achieve a stable and competitive position, a machinebuilding enterprise needs to make timely management decisions that are adequate to changes in the external and internal environment. Therefore, one of the main factors in the development of an organization is the continuous improvement of its quality management system. At the present stage of development of machine-building production, insufficient attention is paid to the issue of methodological support for risk management of quality management system processes developed on the basis of ISO 9000 series standards, despite the fact that this direction is very relevant and practically in demand in all industries.

\section{Equations and mathematics}

The object of research is the quality management system of a machine-building enterprise that implements and develops a quality management system based on ISO 9000 series standards [9].

The subject of the research is the organizational and economic relations that arise in the development, development and implementation of methodological support of the quality management system of a machinebuilding enterprise within the framework of a riskoriented process approach.

The scientific novelty of the research consists of the development of methodological recommendations for improving the quality management system of an enterprise based on a risk-oriented process approach by integrating methods for monitoring the processes of the quality management system and including risk management in the processes of the quality management system [10].

\section{Purpose of the Study}

The aim of the work is the monitoring system, which is based on monitoring process indicators, information about internal audits, self-assessment of the quality management system, allows you to present a real picture of the state of processes and develop management decisions to improve the effectiveness and improvement of processes and the quality management system. And all the information obtained during process monitoring can be used as input data for managing risks in processes.

\section{Research Methods}

The development of theoretical and methodological foundations of the development of the quality management system of a machine-building enterprise based on a risk-oriented process approach has set the corresponding research objectives [7]:

- to analyze modern scientific approaches to the development of the quality management system of a machine-building enterprise based on ISO 9000 standards;

- to suggest the direction of development of the methodology for determining and documenting the processes of the quality management system of a machine-building enterprise in the framework of a riskbased approach [8];

- to substantiate the direction of development of methods for monitoring, measuring, analyzing and influencing the processes of the quality management system of a machine-building enterprise in the framework of a risk-oriented approach;

- to develop a methodology of risk management of quality management system processes in the framework of a risk-oriented process approach;

- to conduct testing of the proposals formulated in the process of solving the tasks set in the branch "NEVZ-Electrotech" LLC "TMH Electrotech".

\section{Findings}

In the course of the study, the following results were obtained, characterized by elements of scientific novelty:

1 It was revealed that the development of the process approach to quality management is reflected in the improvement of ISO 9000 series standards, which require enterprises to constantly improve their quality management system and, accordingly, develop its methodological support.

2 It is proved that the procedure for determining and documenting the processes of the quality management system in the framework of a risk-based process approach required adding the "Process risks" block to the process map and developing an algorithm for describing process risks, including a list of process risks, their level and measures to prevent, reduce or transfer risks [11].

3 It was revealed that in the framework of the riskbased approach, the process manager should include information in the report on the functioning of the process not only about the results of the processes, about the reasons of deviations, developed and implemented corrective actions and corrections, but also information about the effectiveness of actions in relation to risks.

4 The method of risk management of processes of the quality management system of a machine-building enterprise was developed, which included: the algorithm of the risk management process, the methodology of assessing the level of risks and ways to reduce risks [12].

The theoretical significance of the study is that the solutions of conceptual and methodological issues presented in it, develop the scope of application of theoretical aspects of quality management in the direction of developing the organization's quality management system, based on the introduction of a riskbased process monitoring system. 
The practical significance of the research results is that the proposed guidelines can be used by machinebuilding enterprises to improve processes and the quality management system as a whole.

Management development is based on the following scientific approaches:

- system approach;

- process approach;

- risk-based approach.

These scientific approaches are the basis of the ISO 9000 series standards, which are used in the world practice of quality management. ISO 9000 series standards are developed by ISO / TS 176 "Quality management and quality assurance" and are one of the most popular regulatory documents in the world.

Changing the approach to management inevitably led to a revision of the ISO 9000 series standards. According to the report the ISO Survey-2018, in 2018, more than 850 thousand organizations were registered that were certified according to the ISO 9001 standard [13].

The system approach is based on the general theory of systems, founded by Ludwig von Bertalanfi. Such scientists as J. Lorsch, P. Lawrence, and E. G. Yudin made a huge contribution to this scientific direction. For the first time, a theory of systems was applied in the exact sciences, in the late $1950 \mathrm{~s}$ in management (contribution of the school of management science). The main message of the theory is in proper understanding of the functioning of an organization, it must be considered as a system [14].

The key concept in this approach is the concept of a system, which is a certain integrity consisting of interrelated parts, each of which contributes to the characteristics of the whole. The main idea of the system theory is that any decision (action) has consequences for the entire system [15]. A systematic approach to management allows you to avoid a situation where a decision made in one area turns into a problem for another.

The main advantages of such approach consist in merging processes that best help achieve the expected results, the ability to focus on key processes and providing confidence to all parties involved in the efficiency, effectiveness and consistency of enterprise activity.

Risk-based thinking provides confidence that risks are identified, considered, and managed during the design and application of a quality management system. Risk-based thinking is something that we all do automatically in everyday life [16], it implies the implementation a set of agreed measures and methods for managing and controlling numerous risks (positive and negative) by an organization that affect its ability to achieve planned goals [17].

In addition, the release of the fifth edition of ISO 9000 series was also caused by the following reasons. First, over the past period, there have been significant changes in the world management practice, the business environment; new knowledge has been accumulated. Second, new standards for management systems have appeared, which caused the need to create a unified approach. Third, there are some requirements that need to be, for example, such as "mandatory documented procedures" and "documented quality guidelines». Fourth, vertical integration of the organization's management is also needed [18].

The changes made to the new version of the ISO 9001:2015 standard will create a stable set of requirements for the next ten years or more. This set of requirements can remain unchanged in an ever-changing external economic and business environment.

The key changes that have been introduced to the new version of the standard compared to the version of ISO 9001: 2008 are as follows [19]:

1. The structure of the ISO 9001:2015 standard has been changed. The number of sections in the new version has been increased to ten. This extension was made in order to ensure the compatibility of the various standards for management systems. All standards for management systems will have the same structure with the same section names. This structure is defined by the so-called "SL application model" (Annex SL). The goal of creating a unified framework of standards for management systems is to simplify the application of integrated systems (for example, such as ISO 9001, ISO 14001, ISO 27001 and ISO 22301) [20].

2. Departure from classic corrective and preventive actions. Instead, the new version of ISO 9001: 2015 suggests applying a risk management model. This model is more general than the rigid set of actions specified in ISO 9001:2008 (in the sections corrective and preventive actions). Organizations can use the ISO 31000:2018 standard for risk management.

3. Application of the concept of "organization context". The introduction of this concept implies a broader scope of the quality management system. The new version of the standard requires organizations to take into account many factors that can affect the system and its sustainability (external - energy use, materials, procurement, environment, etc., internal-corporate culture, organizational discipline, etc.). All these factors must be taken into account when planning, creating and operating a quality system.

4. Transition from the concepts of "document" (ISO 9001:2008 p.4.2.3) and "records" (ISO 9001:2008 p. 4.2.4) to the concept of "documented information". This transition eliminated the use of documented procedures and quality guidelines. In the new version of ISO 9001: 2015, these documents are not required. Instead, the organization can use various types of documentation (for example, it can be both paper and electronic documents, as well as video and audio recordings).

A machine-building enterprise must develop, implement, maintain and continuously improve a quality management system, including the necessary processes and their interactions. The processes of the quality management system include management processes, resource provision, product lifecycle processes, measurement, analysis, and improvement.

In practice, guidelines of the definition, design and management of quality management system processes are set in the form of process maps. The procedure of the 
process actions can also be issued in the form of an organization's standard, instructions, etc.

The process is controlled using a PDCA cycle:

a) planning (P) - setting $\square$ go $\square$; pl $\square$ nning $\square$ ctivities necessary to achieve the goal; planning work with the calculation of the allocation and allocation of resources necessary to achieve the goal, identifying and considering risks and opportunities for improvement;

b) execution (D) - (execution of the process in accordance with the action plan;

c) verification $(\mathrm{C})$ - monitoring and measurement of the process (where applicable), analysis of the information received;

d) impact of (A) - action on the basis of the conclusions drawn in the previous step, aimed at improvement.

The process is managed by the process manager. At the same time, its responsibilities include:

- documentation of the process in accordance with the requirements of regulatory documents established at the enterprise;

- implementation of process planning based on the company's quality goals and business plan;

- defining the output and input data, criteria, and methods required for effective execution and management of the process;

- planning of the availability of resources needed to complete the process and its set criteria with maximum efficiency;

- implementation of process management with the organization of clear interaction between its stages and between departments;

- evaluating the effectiveness of the process at regular intervals;

- conducting a systematic analysis of the actual values of the criteria and the root causes of process variability at regular intervals;

- analysis of the impact of process variability on the output of non-conforming products;

- identification of the need for corrective actions to improve the performance of the process and increase its effectiveness.
At the same time, the process Manager has the following rights [21]:

- submitting the proposals of improving the quality management system processes to the top management of the company or a representative of the management;

- requirement from departments that ensure the functioning of the process (including those that are not functionally subordinate to the process manager) to provide data for accounting/monitoring and analysis of information on the relevant process;

- giving instructions aimed at improving the process to the heads of departments that ensure its functioning.

The process manager plans the goals, criteria, outputs and inputs of the process, as well as the availability of resources necessary for its implementation, evaluates the process and makes changes necessary to achieve the intended results and improve the process.

When planning processes should be taken into account:

- needs and expectations of stakeholders;

- goals to be achieved;

- criteria necessary to ensure the effective functioning of processes and their management;

- legal and regulatory requirements;

- interactions with other processes;

- required inputs and expected outputs;

- resources and information;

- duties, responsibilities and powers in relation to the process;

- potential risks;

- necessary records;

- monitoring, measurement, analysis, assessment and improvement.

The process manager develops process performance criteria that are used for operational process management, staff motivation, and continuous improvement of the quality management system.

The process is documented by the process manager in the form of a process map, which consists of:

- graphical representation of the process as a diagram describing the process elements;

- tables of process performance criteria (Table 1).

Table 1. Rules for filling out the process map

\begin{tabular}{|c|l|}
\hline $\begin{array}{c}\text { No. of the } \\
\text { element of } \\
\text { a process }\end{array}$ & Content \\
\hline 1 & Title of a process \\
\hline 2 & $\begin{array}{l}\text { A list of the main activities with the designation of the document regulating the process, including monitoring, } \\
\text { measurement, analysis and evaluation of the process, as well as corrective actions, or a link to the flowchart of the } \\
\text { process. A list of processes that are part of a higher-level process, indicating the designations and names of process } \\
\text { maps, or a link to the drawing with the decomposition of the process (if necessary). }\end{array}$ \\
\hline 3 & Designation and name of the higher-level process (if available). \\
\hline 4 & Statement of the process goal. \\
\hline 5 & The position of the head in the process. \\
\hline 6 & $\begin{array}{l}\text { Products or information obtained as a result of the process. Designations and names of processes that process outputs } \\
\text { are directed to. }\end{array}$ \\
\hline 8 & $\begin{array}{l}\text { Names of documents of external origin that regulate the performance of relevant activities and reflect quality } \\
\text { requirements. }\end{array}$ \\
\hline
\end{tabular}




\begin{tabular}{|c|l|}
\hline 9 & $\begin{array}{l}\text { Names of documents of internal origin that regulate the performance of relevant activities and reflect quality } \\
\text { requirements. }\end{array}$ \\
\hline 10 & List of required resources. \\
\hline 11 & Names of performance criteria and (or) a link to the table of performance criteria. \\
\hline 12 & Names and designations of required records and (or) a link to the table of records. \\
\hline 13 & Knowledge required for the operation of the process. \\
\hline
\end{tabular}

In accordance with the proposed risk management procedure, measures were identified, analyzed, evaluated and developed to prevent, reduce or transfer risks of the selected management system processes. Risks were embedded in the processes, so risk maps were not drawn up and risks were included in the process maps [22].

In order to monitor and analyze the functioning of the quality management system processes in the "NEVZElectrotech" branch, performance indicators are set for each process, which are calculated and analyzed with the established process map at regular intervals. If the calculated values do not exceed the set base values, the process is considered effective. In this case, the process manager determines the reasons that led to the failure of the process, develops corrections and corrective actions to eliminate the discrepancy, and also reviews the risks of the process in order to identify previously unaccounted risks and assess the effectiveness of previously developed measures to prevent, reduce or transfer the risk.

The risks of the "Procurement" process, their sources, and measures to prevent, reduce, or transfer the risks are shown in Table 2.

Table 2. Rules for filling out the process map

\begin{tabular}{|l|l|}
\hline \multicolumn{1}{|c|}{ Source of risk } & \multicolumn{1}{c|}{ Measures to prevent, reduce or transfer risk } \\
\hline \multirow{2}{*}{$\begin{array}{l}\text { The volume of planned purchases } \\
\text { was incorrectly determined due to the } \\
\text { variability of information about the } \\
\text { need }\end{array}$} & $\begin{array}{l}\text { Approval of the possibility of providing goods and materials for the conclusion of contracts } \\
\text { for the supply of products and execution of additional agreements. }\end{array}$ \\
\cline { 2 - 2 } & $\begin{array}{l}\text { Approval of adjustments of the plan of the release of commercial products, taking into } \\
\text { account the timing of the formation of the purchase plan for the planned month and the time } \\
\text { to make adjustments. }\end{array}$ \\
\cline { 2 - 3 } $\begin{array}{l}\text { Approval of the maintenance work plan, taking into account the terms of forming the } \\
\text { purchase plan for the planned month and the time to make adjustments. }\end{array}$ \\
\hline $\begin{array}{l}\text { The volume of planned purchases } \\
\text { insufficient staff qualifications }\end{array}$ & Improving the level of competence of employees of the commercial directorate. \\
\hline $\begin{array}{l}\text { Non-fulfillment of the declared } \\
\text { volume by the supplier of goods and } \\
\text { services due to the delivery of non- } \\
\text { conforming products. }\end{array}$ & $\begin{array}{l}\text { Prompt replacement of non-conforming products or delivery from an alternative supplier of } \\
\text { goods and materials. }\end{array}$ \\
\hline $\begin{array}{l}\text { Delivery of non-declared products by } \\
\text { the supplier of goods and materials }\end{array}$ & $\begin{array}{l}\text { Sending the task to the supplier of goods and materials for shipment and control of the range } \\
\text { of products to be shipped at the time of shipment. }\end{array}$ \\
\hline $\begin{array}{l}\text { Stop of production at the supplier of } \\
\text { goods and materials }\end{array}$ & Monitoring the activities of suppliers of goods and materials. \\
\hline $\begin{array}{l}\text { Late delivery of materials and } \\
\text { purchased components }\end{array}$ & $\begin{array}{l}\text { Organization of additional delivery in the shortest possible time (making an additional order, } \\
\text { conducting negotiations, going on a business trip, searching for alternative suppliers, making } \\
\text { a replacement). }\end{array}$ \\
\hline $\begin{array}{l}\text { Disruption of production due to the } \\
\text { termination of the activity of the } \\
\text { supplier of goods and materials }\end{array}$ & Approval of the possibility of changing the product design, modernization. \\
\hline
\end{tabular}

\section{Conclusion}

The research touched the approaches to management based on ISO 9000 series, covered the basics of the formation of the subsystem of risk management of processes of the quality management system and process of risk management, the methods of risk assessment under the risk-oriented process approach the quality management system were considered.

It is revealed that the process monitoring system, which is based on monitoring process indicators, information on internal audits, self-assessment of the quality management system, allows you to present a real picture of the state of processes and develop management decisions to improve the effectiveness and improvement of processes and the quality management system. And all the information obtained during process monitoring can be used as input data for process risk management. Methods of risk management processes of the quality management system of the organization needs to provide flexible management of internal and external risk processes inherent to modern conditions of functioning of the organization. They allow one to move to a continuous risk management processes in conjunction with the operation of the monitoring system processes of the quality management system of the organization. Analysis of risk assessment methods in the framework of the risk-oriented process approach of the quality management system showed that the methodology of managing process risks should be developed and implemented based on the use of such 
quality management methods as FMECA (for general risk assessment and development of control actions), and Ishikawa diagrams (for hazard identification). This will provide a comprehensive scientific approach to risk management

\section{References}

1. W. Mellis. Software quality management in turbulent times - are there alternatives to process oriented software quality management. Softw. Qual. J., 7(3-4), 277-295 (1998)

2. P.B. Petersen. Total quality management and the deming approach to quality management. J. of Manag. Hist., 5(8), 468-488 (1999)

3. I. Shuli. Earnings management and the quality of the financial reporting. Perspect. of Innov., Econ. and Busin., 8(2), 45-48 (2011)

4. S.S. Skobkin, Ya.A. Belavina, G.V. Kalita. Methodological approaches to the formation of the quality management system for hotels in Russian Federation. Int. Rev. of Manag. and Mark., 7(1), 128-136 (2017)

5. F.K. Abdrazakov, S.S. Orlova, T.A. Pankova, E.N. Mirkina, O.V. Mikheeva. Risk assessment and the prediction of breakthrough wave during a dam accident. J. of Interdiscipl. Res., 8(1), 154-161 (2018)

6. L.V. Kireicheva, O.B. Khokhlova. Elemental composition of different fractions from the sapropel organic matter. Euras. Soil Sci., 33(9), 947-949 (2000)

7. N. Fen, D.B. Kozlov, I.S. Rumyantsev. Hydraulic studies of stepped spillways of various design. Pow. Technol. and Eng., 49(5), 337-344 (2016)

8. L.V. Kireicheva, O.A. Zakharova. The effect of cyclic irrigation with wastewater on the properties of gray forest soils. Euras. Soil Sci., 35(9), 990-995 (2002)

9. V.I. Olgarenko, G.V. Olgarenko, I.V. Olgarenko. A method of integral efficiency evaluation of water use on irrigation systems. Int. Multidiscipl. Sci., GeoConf. SGEM, 18(3.1), 3-9 (2018)

10. N.F. Ryzhko, F.K. Abdrazakov, S.N. Ryzhko, S.V. Botov. The increase of qualitative indicators during watering with multiple support sprinklers. J. of Fund. and Appl. Sci., 10(6S), 1482-1497 (2018)

11. D.V. Kozlov. A linear dynamic model for calculating the transverse oscillation of free-floating ice cover. Water Res., 28(2), 215-219 (2001)

12. V.I. Olgarenko, I.V. Olgarenko, V.I. Selyukov. Computer technology of planning water use in irrigation systems. Bull. of the Rus. Acad. of Agricult. Sci., 4, 12-15 (2012)

13. D.V. Kozlov, A.N. Nasonov, I.M. Zhogin, I.V. Tsvetkov. Multifractal principles of aquatic ecosystem development control by algacenosis correction. Water Res., 44(2), 259-266 (2017)
14. M.A. Bandurin, V.A Volosukhin,. A.V. Mikheev, Y.V. Volosukhin, V.V. Vanzha. Finite-element simulation of possible natural disasters on landfall dams with changes in climate and seismic conditions taken into account. J. of Phys. Conf. Ser., 1015, 032011 (2018)

15. B.P. Chesnokov, O.V. Naumova, V.A. Strelnikov, F.K. Abdrazakov, B.A. Tronin. Polyethylene production from granules using high voltage. Int. J. of Appl. Eng. Res., 11, 2140-2144 (2016)

16. V.I. Olgarenko, G.V. Olgarenko, I.V. Olgarenko. Integrated assessment of the technical level of the irrigation and drainage systems. Meliorat. and water manag., 6, 8-11 (2013)

17. D.V. Kozlov, A.N. Nasonov, I.M. Zhogin, I.V. Tsvetkov. Multifractal principles of aquatic ecosystem development control by algacenosis correction. Water Res., 44(2), 259-266 (2017)

18. L.V. Kireicheva, N.P. Karpenko. Evaluation of the efficiency of irrigation in a zonal soil sequence. Euras. soil sci., 48(5), 524-532 (2015)

19. L.V. Kirejcheva et al. New technologies for designing, substantiating the construction, operation and management of land reclamation systems (Publ. House of GNU VNIIA Rus. Agricult. Acad., Moscow, 2010), $240 \mathrm{p}$

20. M.A. Bandurin, V.A. Volosukhin, A.V. Mikheev, Ya.V. Volosukhin, I.P. Bandurina. Finite element simulation of cracks formation in parabolic flume above fixed service live. IOP Conf. Ser. Mat. Sci. and Eng., 327, 022010 (2018)

21. L.V. Kireicheva, F. Yurchenko, V.M. Yashin. Scientific principles of creation and management of reclamation systems in Russia (All-Rus. Res. Inst. of Agrochem., Moscow, 2017), 295 p

22. L.V. Kirejcheva et al. New technologies for designing, substantiating the construction, operation and management of land reclamation systems (Publ. House of GNU VNIIA Rus. Agricult. Acad., Moscow, 2010), $240 \mathrm{p}$ 